\title{
Baicalin attenuates monocrotaline-induced pulmonary hypertension through bone morphogenetic protein signaling pathway
}

\author{
Zhaohua Zhang ${ }^{1}$, Luan Zhang ${ }^{1}$, Chao Sun ${ }^{2}$, Feng Kong ${ }^{2}$, Jue Wang ${ }^{2}$, Qian Xin ${ }^{2}$, \\ Wen Jiang ${ }^{2}$, Kaili Li ${ }^{2}$, Ou Chen ${ }^{2}$ and Yun Luan ${ }^{2}$ \\ ${ }^{1}$ Department of Pediatrics, The Second Hospital of Shandong University, Jinan, China \\ ${ }^{2}$ Central Research Laboratory, The Second Hospital of Shandong University, Jinan, China \\ Correspondence to: Yun Luan, email: y_luan@aliyun.com
}

Keywords: baicalin, pulmonary hypertension, vascular remodeling, NF- $\kappa B, B M P$

Received: January 23, $2017 \quad$ Accepted: June 01, $2017 \quad$ Published: June 28, 2017

Copyright: Zhang et al. This is an open-access article distributed under the terms of the Creative Commons Attribution License 3.0 (CC BY 3.0), which permits unrestricted use, distribution, and reproduction in any medium, provided the original author and source are credited.

\section{ABSTRACT}

Baicalin, a flavonoid compound extracted from roots of Scutellaria baicalensis Georgi (huang qin), it has been shown to effectively attenuates pulmonary hypertension (PH), however, the potential mechanism remains unexplored. In this study, we investigated the potential mechanism of baicalin on monocrotaline (MCT)induced $\mathrm{PH}$ in rats. The results showed that baicalin attenuated lung damage in $\mathrm{PH}$ rat model through inhibiting the pulmonary arterial smooth muscle cell proliferation and induction of cells apoptosis. Furthermore, we demonstrated that baicalin inhibition the expression of nuclear factor-кB (NF-кB) p65 and bone morphogenetic protein (BMP) antagonists gremlin-1, but increased the expression of inhibitor of NF-кB (I-kB $\alpha)$, BMPR2, BMP-4, BMP-9 and Smad1/5/8. Additionally, baicalin suppression endothelialto-mesenchymal transition in PH lung tissue. Collectively, we confirmed that baicalin via inhibition of NF-кB signaling to further activation of BMP signaling to have a therapeutic effect on $\mathrm{PH}$ and providing a promising therapeutic strategy for $\mathrm{PH}$.

\section{INTRODUCTION}

Pulmonary hypertension ( $\mathrm{PH})$ is a lethal syndrome characterized by pulmonary vascular obstruction caused, a sustained elevation of pulmonary pulmonary vascular resistance, vascular remodeling, right ventricular hypertrophy and failure $[1,2]$. The pathogenesis of $\mathrm{PH}$ including pulmonary arterial endothelial cell dysfunction and pulmonary arterial smooth muscle cell (PASMCs) proliferation [3]. The neointimal formation and hyperplasia of the medial vascular wall due to an imbalance between proliferation and apoptosis of PASMCs [4, 5]. Although there are a large number of treatment options for $\mathrm{PH}$, including inhaled nitric oxide, vasodilators, calcium channel blockers, intravenous prostacyclin, and endothelin receptor antagonists, most patients eventually become resistant to therapy and succumb to the disease. Therefore, novel approaches are urgently required for the treatment of $\mathrm{PH}$.

Recent studies revealed that the disorder of bone morphogenetic proteins (BMPs) signaling deregulated the cell growth and differentiation, and contributed to pulmonary artery remodeling in the process of $\mathrm{PH}[6$, 7]. BMPs are multifunctional proteins that regulate cells proliferation, differentiation, and apoptosis, which bind and activate heteromeric complexes of type I and type II receptors. BMPs and there receptors plays a major role in pulmonary hypertension. Type II receptors (BMPR2) significantly decreased in patients with primary $\mathrm{PH}$ and in animal models induced by monocrotaline, chronic hypoxia or transgenic mice [8,9]. BMP4 could regulate the complex receptor signaling pathways associated with BMPRII in distal PASMCs during the process of pulmonary arterial remodeling in PH [10]. BMP9 not only protected pulmonary arterial endothelial cells from apoptosis and promotes vascular stability, but also increased BMPR2 gene expression [11].

Baicalin, a flavonoid compound purified from the dry roots of Scutellaria baicalensis Georgi (huang qin), has several biological effects [12-15]. Moreover, baicalin has therapeutic potential for the treatment of $\mathrm{PH}$ through 
inhibition pulmonary artery pressure and pulmonary vascular remodeling via anti-inflammatory response [12, 16]. In recent years, it has been shown that baicalin can inhibit PAMSCs proliferation and promote apoptosis $[17,18]$. However, the potential mechanism remains unexplored. Here, we investigated the protective role and revealed the underlying mechanism of baicalin against lung damage in MCT-induced $\mathrm{PH}$ rat.

\section{RESULT}

\section{Baicalin attenuates monocrotaline-induced pulmonary hypertension and pulmonary vascular remodeling in rats}

The ventricular systolic pressure (RVSP), right ventricle/left ventricle plus septum $(\mathrm{RV} / \mathrm{LV}+\mathrm{S})$ ratio and pulmonary arterial pathological were used to evaluate the model of MCT-induced PH. The results showed that there were significant decrease in RVSP and RV/LV $+\mathrm{S}$ in $\mathrm{PH}+$ baicalin rats than MCT-induced $\mathrm{PH}$ rats $(P<0.05$; Figure $1 \mathrm{~A}$ and $1 \mathrm{~B})$. To evaluate pulmonary vascular remodeling, the medial thickness of the pulmonary arterial was detected, H\&E staining showed a significant decrease in the thickness of the pulmonary vascular walls in the smooth muscle layer of pulmonary arterioles in $\mathrm{PH}+$ baicalin rats than in $\mathrm{PH}$ rats $(P<0.05$; Figure $1 \mathrm{C}$ and $1 \mathrm{D})$.

\section{Anti-inflammatory response of baicalin in rat lung tissue}

The expression of proinflammatory cytokine / chemokine genes tumor necrosis factor- $\alpha$ (TNF- $\alpha)$, the interleukin (IL)-6 and IL-1 $\beta$ were detected by quantitative real-time polymerase chain reaction (qRT-PCR). Our results showed that the mRNA expression of TNF- $\alpha$, IL6 , and IL-1 $\beta$ was increased in lung in MCT-induced rats than control, however, when the rats were treatment with baicalin, the mRNA expression of TNF- $\alpha$, IL- 6 , and IL-1 $\beta$ was significantly reduced when compared with $\mathrm{PH}$ rats $(P<0.05$; Figure 1E).

\section{Effects of baicalin on BMP-related signaling molecules expression in the lungs}

To determine the alteration of cell signaling molecules contributed to the baicalin in MCT-induced $\mathrm{PH}$ rat, the expression of NF- $\mathrm{B}-\mathrm{BMP}$ signaling axis molecules were determined. Our results showed that when the rats were treatment with baicalin, the mRNA expression of I $\mathrm{B}-\alpha$, BMPR2, BMPs-2/4/9, Id 1 and Id3 were significantly increased, but the mRNA expression of NF- $\kappa \mathrm{B}$ p65 was decreased in lung than in MCT$\mathrm{PH}$ rats $(P<0.05$, Figure $2 \mathrm{~A})$. Mover over, western blot results showed that the protein expression of $\mathrm{I} \kappa \mathrm{B}-\alpha$,
BMPR2, BMPs-4/9 were up-regulation, but the protein expression of $\mathrm{NF}-\kappa \mathrm{B}$ p $65, \mathrm{p}-\mathrm{NF}-\kappa \mathrm{B}$ p65 and the ratio between phospho and total NF-kB p65 (p-p65/p65) were down-regulation in baicalin $+\mathrm{PH}$ group than in $\mathrm{PH}$ group $(P<0.05$, Figure 2B, 2C, 2D and 2E).

The BMP antagonist, gremlin 1 was also measured in lungs, there was a significantly down-regulation of gremlin 1 protein expression in $\mathrm{PH}+$ baicalin lung compared with $\mathrm{PH}$ group $(P<0.05$, Figure $3 \mathrm{~A})$. Furthermore, the BMP related TGF- $\beta 1 / \mathrm{Smad}$ signaling molecules were also detected, the present study showed that the protein expression levels of TGF- $\beta 1$ and the ratio of phospho-Smad2 to total Smad2 were significantly reduced, but the ratio of phospho-Smad $1 / 5 / 8$ to total Smad $1 / 5 / 8$ was significantly increased in the lung when the $\mathrm{PH}$ rats were treatment with baicalin than $\mathrm{PH}$ rats, which is consistent with reduced BMP signaling $(P<0.05$, Figure 3B, 3C and 3D).

\section{Apoptotic effects of baicalin in vivo and vitro}

RT-PCR results showed that the mRNA expression of antiapoptotic gene $\mathrm{Bcl} 2$ was up-regulated in the $\mathrm{PH}$ rats, the proapoptotic genes caspase-3 and the ratio of $\mathrm{Bax} / \mathrm{Bcl} 2$ were down-regulation when the MCT-PH rats were treatment with baicalin $(P<0.05$, Figure 4A). Western blot results showed that the expression of protein levels of Bcl-2, Bax and caspase-3 were consistent with mRNA expression $(P<0.05$, Figure 4B).

Mover over, apoptosis in vivo were determined by flow cytometry staining with Annexin V/FITC and a One Step TUNEL apoptosis assay kit (Beyotime Institute of Biotechnology, Shanghai, China) according to the protocol. In the control group, the median percentage of apoptotic PAMSCs was $13.21 \%$, MCT treatment in the rats resulted in increased percentage of apoptotic PAMSCs to $4.51 \%(P<0.01)$. The baicalin showed a significant reduction of apoptotic PAMSCs to $30.25 \%$, compared with the MCT-treated PH group $(P<0.05$, Figure 5A).

The morphologic changes in PAMSCs by TUNEL staining showed that there was a significantly decreased of apoptosis in $\mathrm{PH}+$ baicalin group when compared with $\mathrm{PH}$ group $(P<0.01$, Figure 5B).

\section{Antiproliferative effects of baicalin in vivo and vitro}

Cell viability and population were analyzed to demonstrate the effect of baicalin on PASMCs proliferation in vivo. Our results showed that the cell viability was increased and the population was decreased in MCT PH group compared with the control group, however, these change were obviously inhibited in $\mathrm{PH}+$ baicalin group when compared with $\mathrm{PH}$ group $(P<0.05$, Figure 6A and 6B). 
Moverover, the number of PCNA as a marker of cell proliferation was detected in vitro. Immunohistochemistry of rat lung sections suggested that the number of PCNA positive cells in hypertrophied arteries was obviously reduced in $\mathrm{PH}+$ baicalin group conpared with $\mathrm{PH}$ group (Figure 6C).

\section{Effects of baicalin on MCT-induced endothelial- to-mesenchymal transition in lung}

RT-PCR exhibited a marked reduction in the pulmonary arterial endothelial cell markers CD31 and vascular endothelial cadherin (E-cadherin), however, the mesenchymal markers $\alpha$-smooth muscle actin ( $\alpha$-SMA) was significantly increased in MCT PH rat. Furthermore, immunohistochemical andimmunofluorescence also showed a significantly decreased in the expression of CD31 but increase in the expression of $\alpha$-SMA in MCT $\mathrm{PH}$ group compared with the control group. However, all of these changes were restored in $\mathrm{PH}+$ baicalin rats compared with $\mathrm{PH}$ rats $(P<0.05$, Figure 7$)$.

\section{DISCUSSION}

Our results for the first time demonstrated that intragastric administration of baicalin significantly attenuates MCT-induced pulmonary hypertension and pulmonary vascular remodeling, the protective mechanism may be through activation of BMP signaling and associated with anti-inflammatory response, induction
A

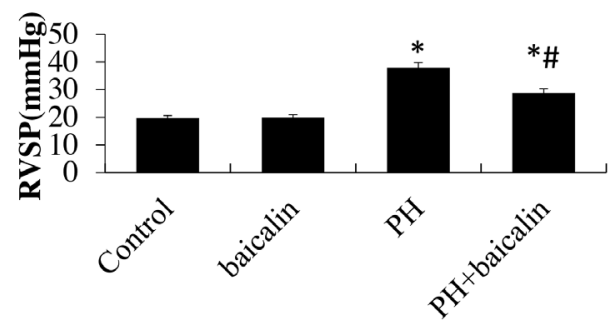

C
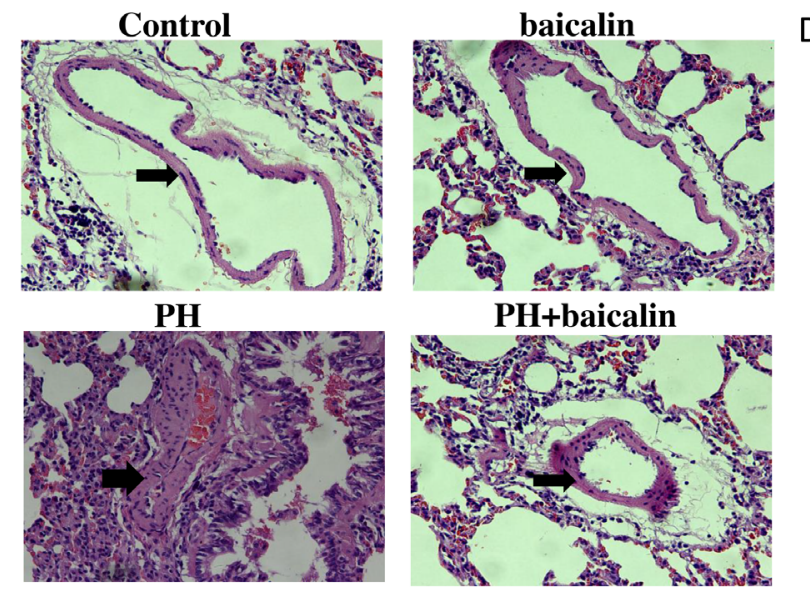

B

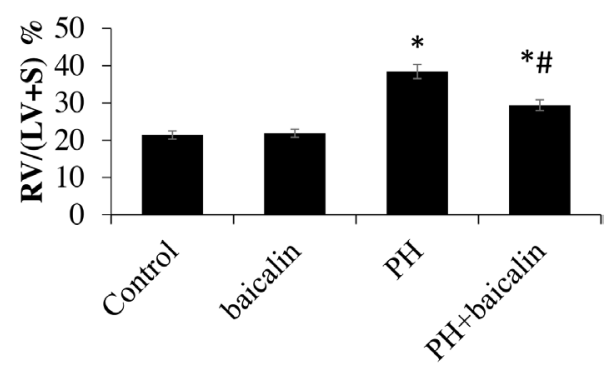

D

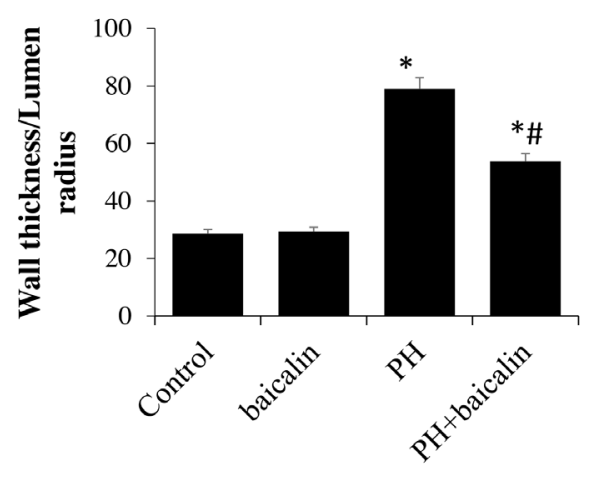

$\mathrm{E}$



Figure 1: Effect of baicalin on MCT-induced pulmonary hypertension and expression of proinflammatory cytokine genes. (A) A comparison of the right ventricular systolic pressure (RVSP) in each group. (B) A comparison of the ratio of right ventricular weight to left ventricle plus septum $(\mathrm{RV} / \mathrm{LV}+\mathrm{S})$ in in each group. (C) Representative hematoxylin and eosin staining images in each group. (D) A comparison of the medial thickness of the pulmonary arterial walls in each group. (E) mRNA expression levels of tumor necrosis factor- $\alpha$, interleukin (IL)-6, and IL-1 $\beta$ detected using quantitative real-time polymerase chain reaction. ${ }^{*} P<0.05 v s$. control; ${ }^{\#} P<0.05 v s$. $P H$ group. 
cells apoptosis, reduction proliferation and reversal EndoMT process. These provides the following evidences in regards to the mechanism of baicalin inhibition MCTinduced $\mathrm{PH}$.

$\mathrm{PH}$ is a severe clinical condition associated with a poor prognosis and high mortality, characterized by narrowing and obliteration of precapillary pulmonary arteries, secondary to proliferation and apoptosis resistance of endothelial cells, smooth muscle cells, and fibroblasts. Previous reports $[11,19,20]$ have demonstrated that pulmonary vascular structural remodeling of the distal pulmonary vasculature is considered to be the major pathological basis of hypoxic pulmonary hypertension, however, the exact mechanism of remodeling has not yet been fully elucidated. So far, no effective therapy is available for $\mathrm{PH}$. NF- $\mathrm{NB}$ is a key transcriptional regulator factor, plays a key role in the process of vascular remodeling in a variety of physiological and

A



B
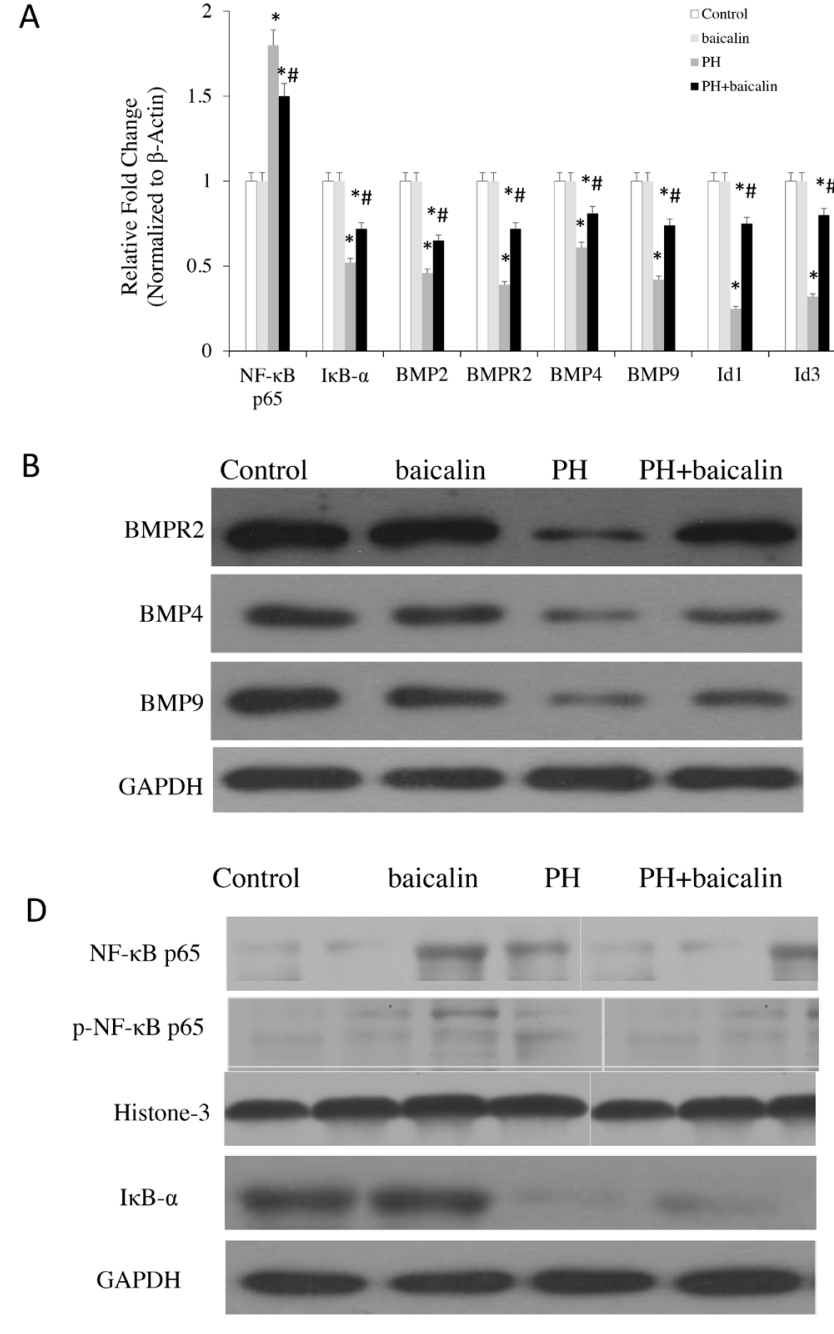

pathophysiological states [21, 22]. Inhibition of NF$\kappa \mathrm{B}$ in the lungs can reduce the endothelial damage, attenuates the expression of infiltrating molecules, and restores the RV pressure. Previously, we demonstrated that baicalin could protect lung damage caused by MCT, inhibit the pulmonary artery pressure, reduce right ventricular hypertrophy, and attenuate pulmonary vascular remodeling, the mechanism was through inhibition of NF$\kappa \mathrm{B}$ signaling pathway related anti-inflammatory response [13], however, the further signal path mechanism is unclear.

BMPR2 mutations have been reported in more than $70 \%$ of heritable cases of $\mathrm{PH}$ and approximately $20 \%$ of apparently sporadic cases of idiopathic PH [23, 24]. Loss of BMPR 2 or dysfunction of BMP signaling were associated with the occurrence of $\mathrm{PH}$ [11]. BMPs involved in a wide range of cell function including proliferation, migration, differentiation, and apoptosis. Mounting
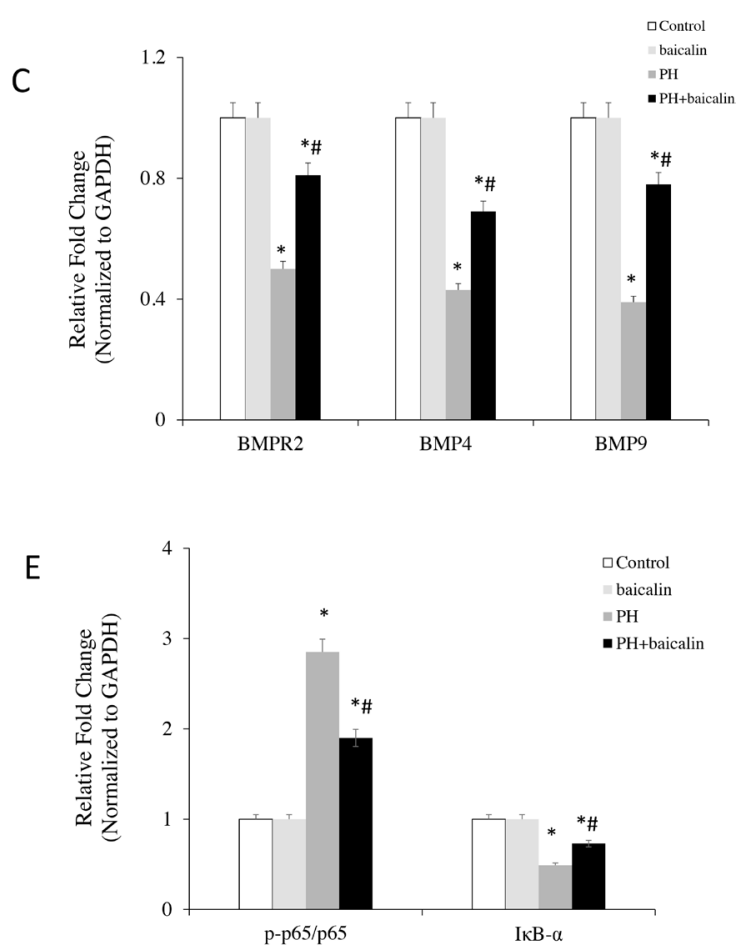

Figure 2: Effected of baicalin on NF-кB/BMP-related signaling molecules expression in the lungs. (A) The mRNA level

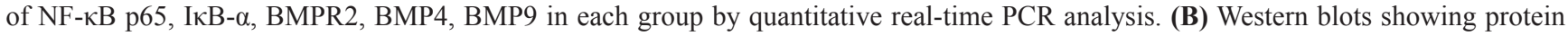
expression of BMPR2, BMP4, BMP9 in each group. (C) Normalized band intensity quantification showing the fold change of the BMPR2,

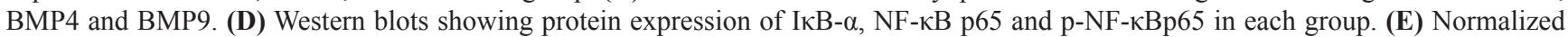

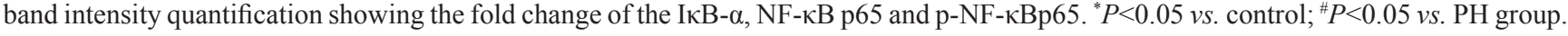


A
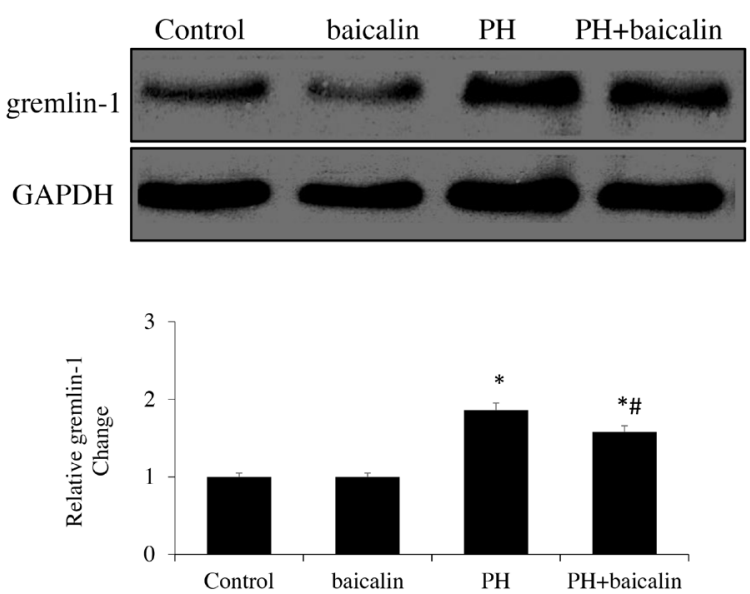

C
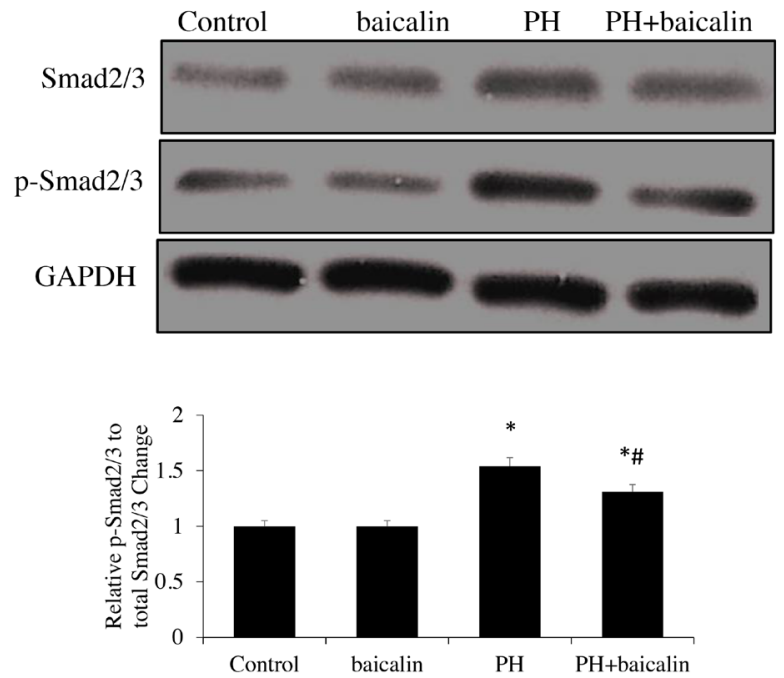
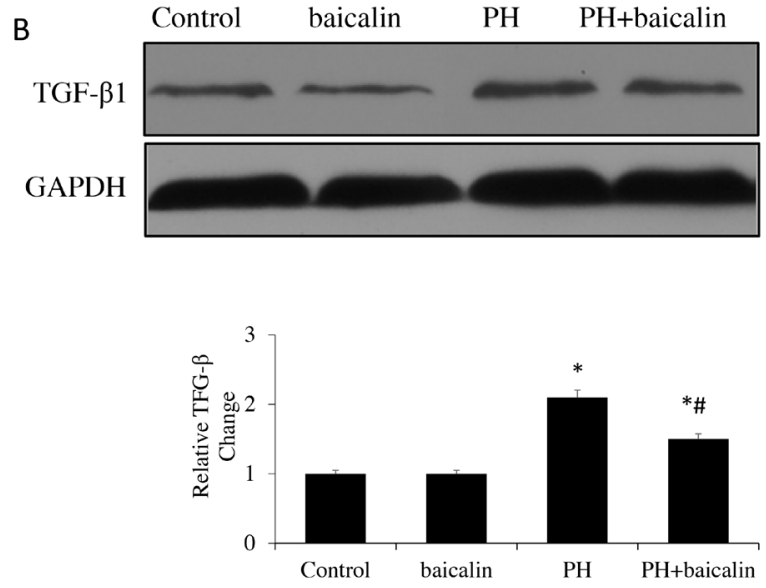

D

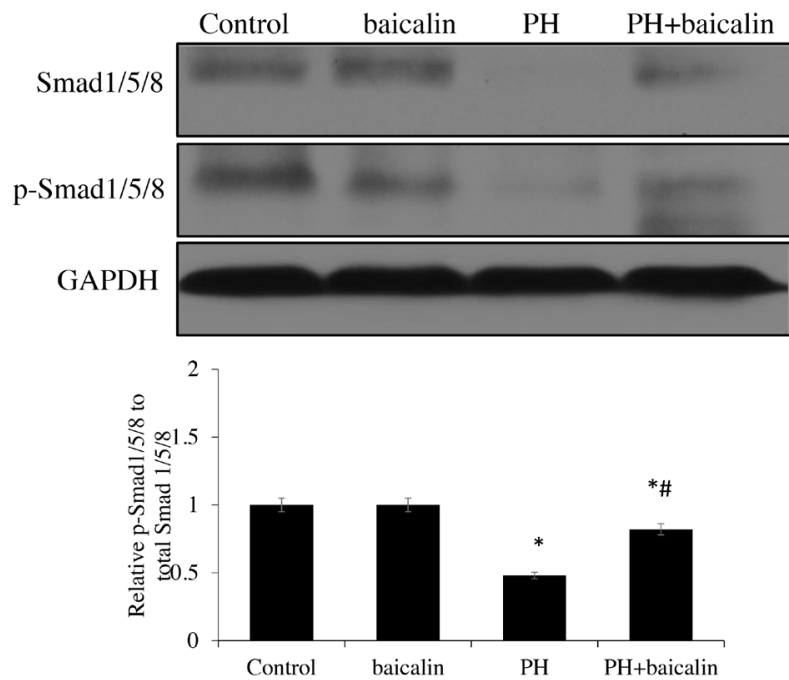

Figure 3: Effected of baicalin on protein expression of TGF-ß1/Smads-related in lung. (A) Western blots showing protein expression of TGF- $\beta 1$. (B) Representative protein expression of gremlin-1. (C) Representative protein expression of Smad2/3 and p-Smad2/3. (D) Representative protein expression of Smad1/5/8 and p-Smad 1/5/8 ${ }^{*} P<0.05$ vs. control; ${ }^{~} P<0.05$ vs. PH group.
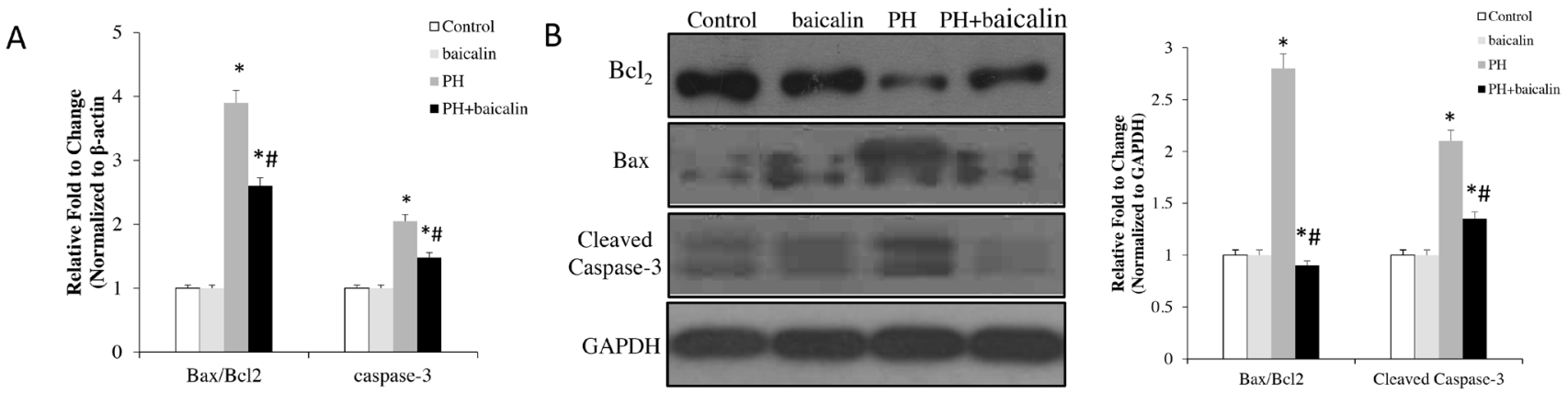

Figure 4: Effected of baicalin expression of apoptotic family genes in lung. (A) Quantitative real-time PCR analysis of the mRNA expression of Bax/Bcl2 ratio and the level of cleaved caspase-3. (B) Western blots showing protein expression of Bcl2, Bax and cleaved caspase-3. Normalized band intensity quantification showing Bax/Bcl2 ratio and the level of cleaved caspase-3. * $P<0.05$, vs. control; ${ }^{*} P<0.05$, vs. PH group. 
evidence indicates that several BMPs, including BMPR2, BMP4 and BMP9 play as an important role during endocrine regulator of pulmonary arterial remodeling, cardiovascular, metabolic, and haematopoietic function [8-11]. BMPR2 signaling as a cause of increased proliferation of PASMCs playing an important role in the remodeling of pulmonary resistance vessels in $\mathrm{PH}$ [24], BMP9 could protect pulmonary arterial endothelial cells from apoptosis and promotes vascular stability, increase BMPR2 gene expression, and further enhancement of BMPR2 signaling.

The induction of inhibitor of DNA binding protein (Id) expression by BMP contributes to its pro-angiogenic response. Regulation of Id proteins by BMPs, with relevance to $\mathrm{PH}$, play an main effect in the smooth muscle cell function [23]. Id family of transcription factors, especially Id1 and Id3 as important functional targets of BMP signaling, are potently regulated by BMP signalling in PAMSCs and might play a complementary and partially redundant role in regulating cell cycling in vascular and other tissues [25, 26]. Id family of transcription factors as important functional targets of BMP signaling, with relevance to $\mathrm{PH}$, both $\mathrm{Id} 1$ and $\mathrm{Id} 3$ were downregulated in the lungs along with BMPR2 in MCT rats $[27,28]$. In the present study, our data corroborated with the association of BMPs with $\mathrm{PH}$, the results demonstrate the expression levels of BMP signaling related protein molecules BMP2, BMP4, BMP9, BMPR2, Id1 and Id3 were restored when the $\mathrm{PH}$ rats were treatment with baicalin compared with the $\mathrm{PH}$ rats. Reports have previously showed a direct association of NF- $\kappa \mathrm{B}$ with BMP signaling in the lungs of MCT PH, inhibition of NF- $\mathrm{BB}$ attenuated $\mathrm{PH}$ and RVH by regulating BMPR2-Id axis gene in heart $[12,27]$. In this report, we further confirmed that $\mathrm{NF}-\kappa \mathrm{B}$ signaling were downregulated in the $\mathrm{PH}+$ baicalin group than $\mathrm{PH}$ group. Together, our data indicate the association of NF- $\mathrm{BB}-\mathrm{BMP}$ signaling with the protection of baicalin on MCT-inducced $\mathrm{PH}$ and pulmonary vascular remodeling.

In PH, PASMC proliferation is enhanced and apoptosis suppressed [29], previous reports have showed that a major consequence of BMPR2 mutation in PASMCs is loss of the growth suppressive effects of BMPs [30, 31]. In PAMSCs, BMPR2 mutation, leads to a proproliferative, apoptosis-resistant cell phenoype, that may contribute to the process of vascular obliteration observed in $\mathrm{PH}$. In this study, we found that when the MCT rats were treatment with baicalin, the mRNA and protein expression levels of antiapoptotic gene $\mathrm{Bcl} 2$ was increased, but the proapoptotic genes, such as caspase-3 and Bax, was decreased in the PAH lung tissue. Importantly, our results in vitro also showed that baicalin could inhibit the MCTinduced proliferation and enhance apoptosis in PAMSCs.

A



Annexin

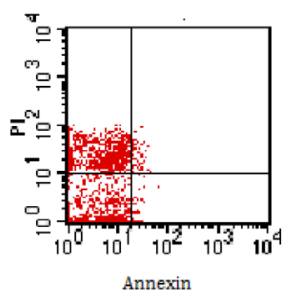

DAPI

$B$

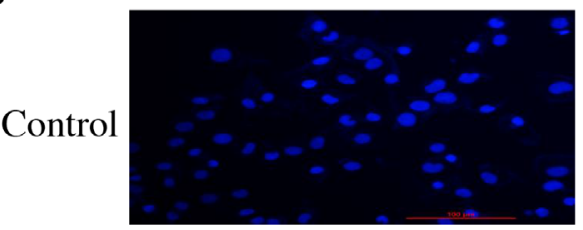

PH
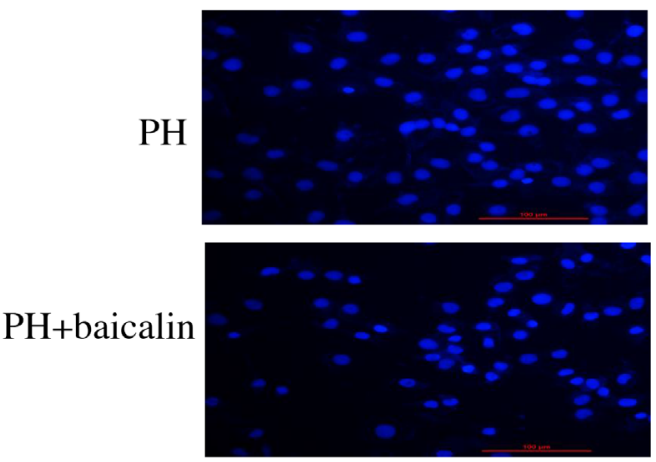

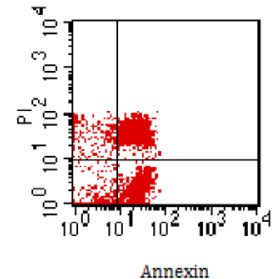

TUNEL

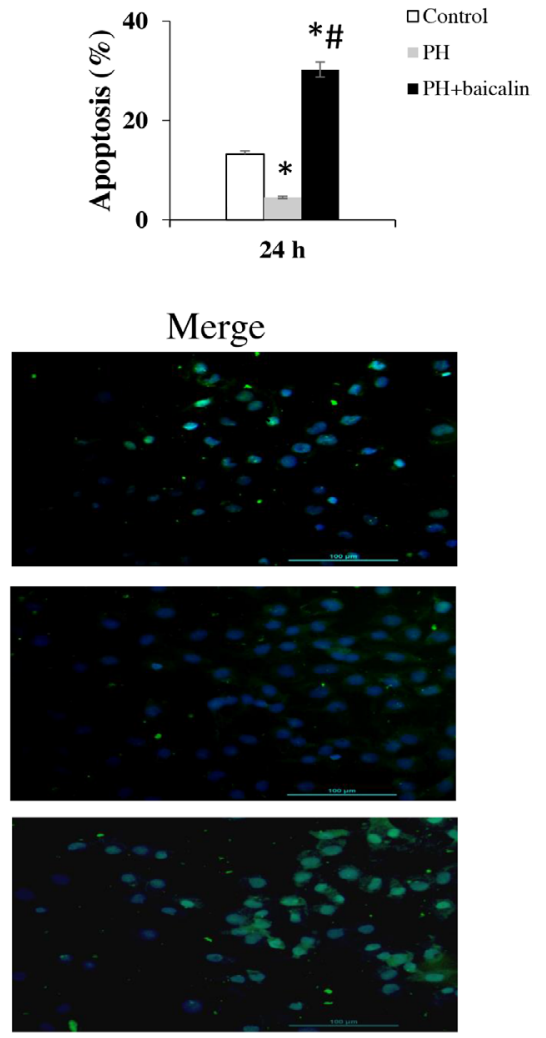

Figure 5: Effected of baicalin on apopotosis. (A) Apoptosis of pulmonary arterial smooth muscle cell was determined by flow cytometry staining for Annexin V/FITC. (B) Cell apoptosis detection by TUNEL staining. ${ }^{*} P<0.05$, vs. control; ${ }^{\sharp} P<0.05$, vs. PH group. 
Collectively, these data suggested that the mechanism of baicalin promote apoptosis and inhibit proliferation in MCT-PH in vivo and vitro is likely to be relevant with BMP signaling. Recent studies have shown that BMP signaling is tightly regulated by inflammatory mediators/ inflammation [32, 33]. Inflammatory cytokines are associated with the pathogenesis of $\mathrm{PH}$, inflammatory molecules (TNF- $\alpha$, IL-6 and IL-1 $\beta$ ) were significant infiltration of macrophages and accumulation in the mice treated with MCT $[34,35]$. TNF- $\alpha$ stimulation reduced the expression of BMP2 and BMPR-II, promote excessive PASMC proliferation and pulmonary vascular remodeling in the setting of BMPR-II deficiency in PASMCs [29]. We have previously identified the link with anti-inflammatory effects of baicalin on MCT PH rats. Mover over, our present study at least part suggested that mechanism of baicalin anti-inflammatory in PH through activation BMP signaling and inhibition pulmonary vascular remodeling in PAMSCs.

BMP antagonists, such as gremlin and noggin, are potentially important mediators of vascular changes in hypoxic pulmonary hypertension, have been implicated plays an key role in the pathophysiology of pulmonary arterial hypertension $[32,36]$. Down-regulates of BMP/ Smad signaling by antagonists binding directly to BMP molecules leads to a reduction in $\mathrm{Smad1/5/8}$ pathway and to a concomitant increase in $\mathrm{Smad} 2 / 3$ pathway. The balance between TGF- $\beta 1$ and BMP signaling also plays an important role in pulmonary fibrosis, TGF- $\beta 1$ and BMP signal through a heteromeric cell surface serine/threonine kinase complex, resulting in the receptor-mediated phosphorylation and activation of $\mathrm{Smad} 2 / 3$, or Smad1/5/8 (BMPs) transcription factors and alterations in gene transcription [37]. Loss of BMPR2 function in PASMCs
A

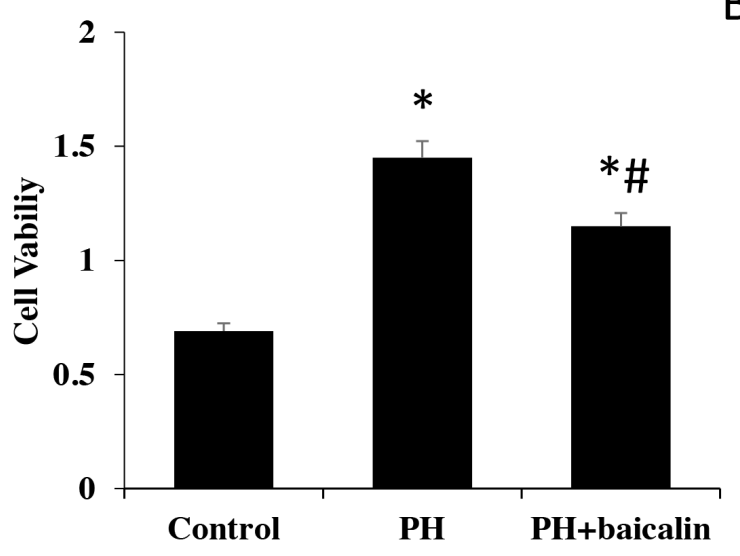

B

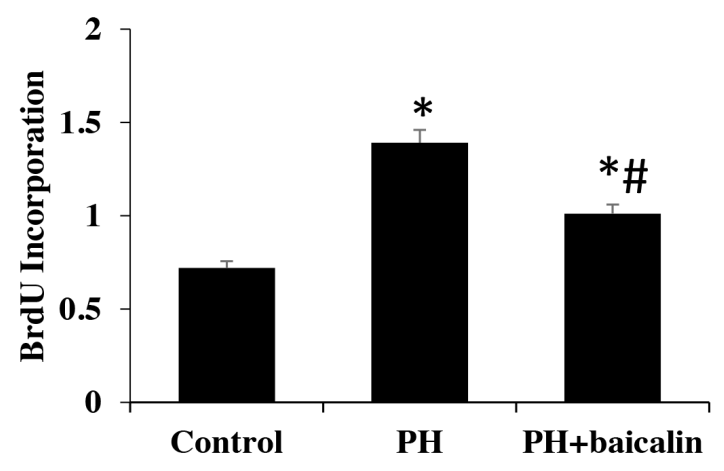

C

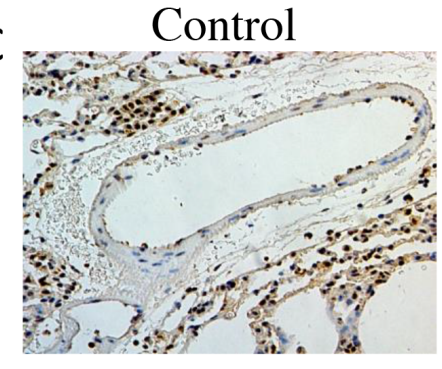

$\mathrm{PH}$



baicalin



PH+baicalin

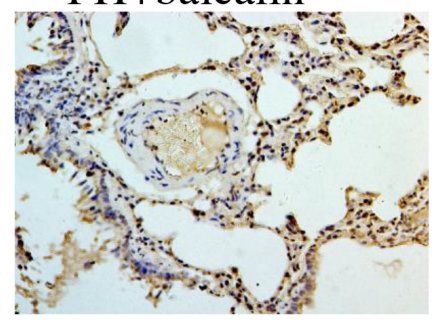

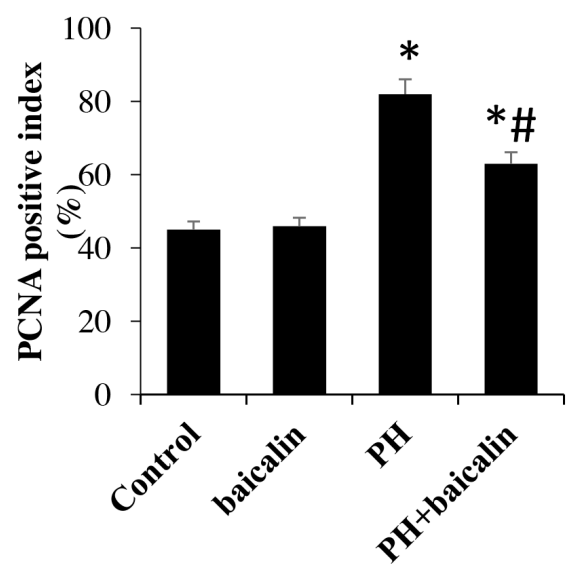

Figure 6: Effected of baicalin on pulmonary arterial hypertension smooth muscle cell proliferation. (A) Cell viability was determined by MTT. (B) Population of cells was analyzed using a DNA BrdU incorporation assay. (C) PCNA in lung was detected by immunohistochemistry. ${ }^{*} P<0.05$, vs. control; ${ }^{\#} P<0.05$, vs. PH group. PCNA: proliferating cell nuclear antigen. 

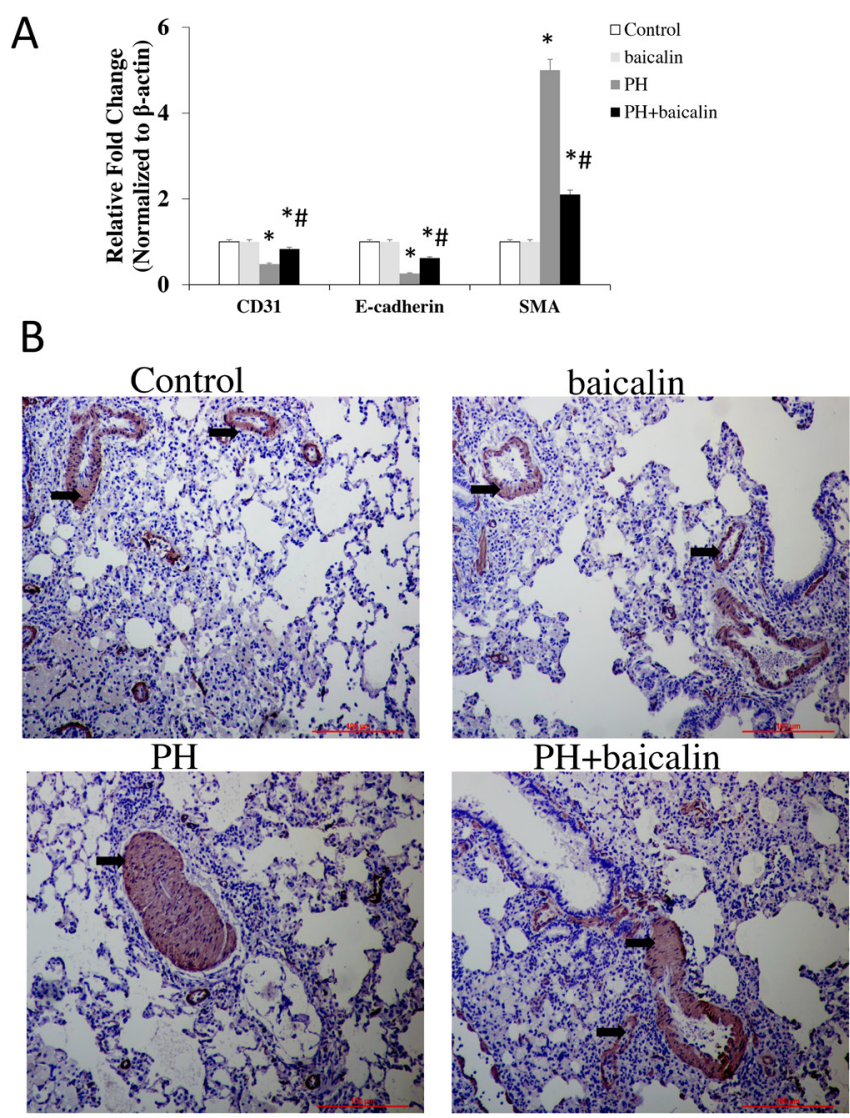

$\mathrm{PH}+$ baicalin
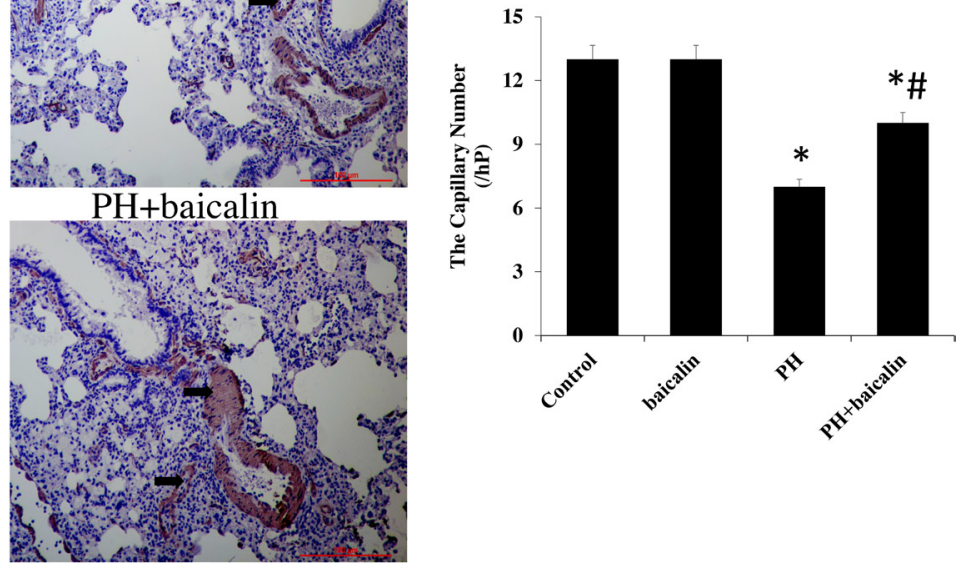

C


Figure 7: Effected of baicalin on MCT-induced endothelial-to-mesenchymal transition in lung. (A) Quantitative real-time PCR detected the mRNA expression of pulmonary arterial endothelial cell markers CD31, and vascular endothelial cadherin E-cadherin, and $\alpha$-SMA. (B) Immunohistochemical detected the expression of CD31. (C) Immunofluorescence detected the expression of $\alpha$-SMA. $P<0.05$, vs. control; ${ }^{\sharp} P<0.05$, vs. PH group. 
reduces phosphorylation of downstream Smad1/5 proteins, one of the major transcriptional targets of BMP/Smad signaling is Id protein [28]. In this report, our data showed that baicalin significantly reduced the protein expression of gremlin 1, TGF- $\beta 1$, the ratio of phospho-Smad 2 to total Smad2, but significantly increased the ratio of phosphoSmad $1 / 5 / 8$ to total Smad $1 / 5 / 8$ in the PH rats. These data provide a strong evidence for the association of BMPs with the inhibitory effect of baicalin on MCT-induced $\mathrm{PH}$, the mechanistic link between BMPs/Smads axis and $\mathrm{NF}-\kappa \mathrm{B}$ during development of $\mathrm{PH}$ and pulmonary vascular remodeling remains unclear and warrants future investigation.

In order to further investigation the mechanism of baicalin on BMP signaling, endothelial to mesenchymal transition (Endo-MT) process was also evaluated. EndoMT is a developmental process characterized by the acquisition of mesenchymal phenotype, such as $\alpha-S M A$, and lose their surface marker protein, such as CD31 and vascular endothelial cadherin. Endo-MT has also been investigated for its potential role in vascular remodeling and the fibrotic lung disease [38-40]. Recently studies $[21,41]$ have showed that Endo-MT is associated with the expression of BMPR2, the dysregulation of BMPR2 signaling may initiate pulmonary endothelial cell apoptosis, Endo-MT is partially ameliorated by stimulating BMPR2 signaling even in the presence of TGF- $\beta 1$. In this study, we found that a loss of vascular endothelial cadherin and CD31 and a gain of $\alpha$-SMA expression in MCTinduced $\mathrm{PH}$, which was reversed in baicalin rats. Taken together, we indicated that the protection of baiclin on MCT-induced PH was through suppression the Endo-MT procession and the under mechanisms was also associated with regulating BMP signaling pathways.

In conclusion, our results showed for the first time that baicalin could protection against lung damage and repair pulmonary vascular remodeling via activating BMP signaling pathways in MCT-induced $\mathrm{PH}$ rats in vivo and vitro. The present study indicated that bacalin possesses the abilities to anti-inflammatory response, inhibition cell proliferation and increase cell apoptosis, the underlying mechanism was associated with link BMPs/Smads axis and NF- $\kappa \mathrm{B}$ signaling, which may trigger Endo-MT events in the lungs. These given new insights into the mechanisms of baicalin in MCT-indeced $\mathrm{PH}$ and identifies as a promising therapeutic target for PH patients.

\section{MATERIALS AND METHODS}

\section{Animal protocol and cell culture}

Male Wistar rats weighing $200 \mathrm{~g}$ to $250 \mathrm{~g}$ were purchased from animal experimental center of Shandong University, China. All animals received humane care in compliance with the Guide for the Care and Use of
Laboratory Animals published by the U.S. National Institute of Health (NIH Publication No. 85-23, revised 1996). The study protocol was approved by the Institutional Animal Care and Use Committee (IACUC) of Shandong University, Shandong, China, and the experiments were conducted according to the Guidelines of the American Physiological Society.

The pulmonary arteries were removed from the lungs of adult rats. PASMCs were obtain from obviously report. Briefly, the cells were cultured in smooth muscle growth media (SMGM-2, Clonetics), supplemented with $5 \%$ fetal bovine serum (FBS), 1\% streptomycin, and $1 \%$ penicillin. Cellular purity was $>85 \%$, as evaluated by morphological appearance under phase-contrast microscopy and immunofluorescence staining for $\alpha$-actin under confocal microscopy. Cells were used between passages 3 and 6 for this study.

\section{Experimental protocols}

Baicalin (purity >95\%) was purchased from Sigma (St. Louis, MO, USA) and was dissolved in dimethyl sulfoxide (DMSO). The PH model was induced by intraperitoneal injection of $60 \mathrm{mg} / \mathrm{kg}$ MCT (Sigma-Aldrich, USA) as we described previously with modifications. Forty animals were randomly assigned to 4 groups: Control, Control+baicalin, $\mathrm{PH}$ and $\mathrm{PH}+$ baicalin groups $(\mathrm{n}=10$ in each). Baicalin groups were given baicalin $100 \mathrm{mg} / \mathrm{kg}$ by intragastric administration from 2 days after MCT injection. PASMC culture were divided into 3 group according to the the cells were obtained from different animals: control, $\mathrm{PH}$ and baicalin group. Cell viability was analyzed by 3-(4, 5-Dimethylthiazol-2-yl)-2, 5-diphenyltetrazolium Bromide (MTT). Cell proliferation was assessed using a DNA BrdU incorporation assay (Roche Applied Science, Burgess Hill, UK). Briefly, cells were seeded into 96-well cell culture plates at a density of $1 \times 10^{4}$ cells. BrdU was incorporated into proliferating cells according to the manufacturer's protocol. The absorbance of the plate was measured by a spectrophotometer microplate reader at a dual wavelength of $450 / 550 \mathrm{~nm}$.

\section{Determination of PH model}

30 days after MCT injection, the experimental rats were anesthetized with pentobarbital $(30 \mathrm{mg} / \mathrm{kg}$, ip, Sigma Aldrich) and inserted with a 3F-Miller micro tip catheter via the right jugular vein into the right ventricle to obtain the right ventricular systolic pressure (RVSP). Results of the hemodynamic parameters, right ventricular hypertrophy, and pulmonary arterial pathological changes were used to evaluate whether the model of pulmonary arterial hypertension was successfully established. The ratio of right ventricular weight to left ventricle plus septum $(\mathrm{RV} / \mathrm{LV}+\mathrm{S})$ was calculated to measure right ventricular hypertrophy. 


\section{Immunological and immunohistochemical analyses}

The rats were sacrificed after hemodynamic measurements, and the lung and heart were quickly harvested and fixed in situ via the trachea cannula with buffered $4 \%$ formaldehyde, and embedded in paraffin. The sections were cut into 4-5 $\mu \mathrm{m}$ slices and were stained with streptavidin peroxidase and hematoxylin and eosin (H\&E). For immunohistochemistry, 4-5 $\mu \mathrm{m}$-thick cryosections or PAMSCs were first blocked with 5\% goat serum (ab7481; Abcam, Cambridge, UK) for $30 \mathrm{~min}$. The sections were then incubated with proliferating cell nuclear antigen (PCNA) (ab18197, Abcam) and CD31 (ab28364; Abcam). Subsequently, the 3, 3'- diaminobenzidine (DAB) dye was added to visualize the antibodies, and following washing of the tissue sections with phosphate-buffered saline (PBS) solution, the sections were observed and photographed under a microscope. For immunofluorescence, the sections or cells were incubated with rabbit polyclonal to smooth muscle $\alpha$-actin ( $\alpha$-SMA, ab5694) or a nonspecific IgG antibody for $1 \mathrm{~h}$ at room temperature, which was followed by $1-\mathrm{h}$ incubation in the dark with florescence isothiocyanate-conjugated goat anti-rabbit secondary antibody (ZF-0311; ZSGB-Bio Co., Beijing, China). Fluorescent images were taken with a Nikon Eclipse 90i microscope. Cells were fixed and permeabilized in a 50\%.

\section{RNA extraction and quantitative real-time polymerase chain reaction}

Total RNA was extracted using RNeasy kit (Qiagen, Valencia, CA) and reverse transcription was performed using iScript cDNA synthesis kit (Bio-Rad, Hercules, CA) according to the manufacturer's instructions. Quantitative real-time polymerase chain reaction(qRT-PCR) analysis was performed to detect the relative pulmonary expression levels of BMP2, BMP4, BMP9, BMPR2, Id1, Id3, Bax, Bc12, caspase-3 CD31, $\alpha$-smooth muscle actin ( $\alpha$-SMA), E-cadherin and TNF- $\alpha$, IL- 6 , and IL- $1 \beta$ using genespecific primers as described previously.

\section{Western blot}

Lung tissue were pulverized in liquid nitrogen and cytosolic, and nuclear proteins were extracted using NE-PER nuclear and cytosolic extraction reagents (Pierce). Protein extraction buffer and equal amounts of protein were denatured and separated by sodium dodecyl sulfatepolyacryl-amide gel electrophoresis (SDS-PAGE). Protein concentrations were assessed using the BCA Protein Assay kit (Santa Cruz Biotechnology). $10 \mu \mathrm{g}$ of total protein were electrophoresed on $4-20 \%$ gradient SDSPAGE gels and transferred to a nitrocellulose membrane. Western blotting and the subsequent quantification of each blots was performed, as described previously. The primary antibodies used in this study include BMPR2 (ab170206),


(ab86299), BMP4 (ab39973), BMP9 (ab35088), gremlin (sc-18274), transforming growth factor- $\beta 1$ (TGF- $\beta 1$; ab25121), Smad2/3 (sc-133098), p-Smad2/3 (sc-11769), Smad1/5/8 (sc-6031), p-Smad1/5/8 (sc-12353), Bax (ab32503), Bcl2 (ab59348), cleaved caspase-3 (ab13847), Histone H3 (ab8898) and GAPDH (ab181602).

\section{Flow cytometry}

The Annexin V-FITC/PI apoptosis detection kit according to the manufacturer's instructions (Roche Diagnostics, Indianapolis, IN, USA). Briefly, PAMSCs were seeded in 6 -well plates. $1 \times 10^{6}$ cells were collected and suspended in $500 \mu \mathrm{l}$ binding buffer, and $5 \mu \mathrm{l}$ Annexin V-FITC and $5 \mu$ PI were added to each sample and incubated in the dark for $15 \mathrm{~min}$. The cell surface phosphatidylserine in apoptotic cells was quantitatively estimated by using Annexin V/FITC apoptosis detection kit according to manufacturer's instructions (Roche Diagnostics).

\section{Terminal deoxynucleotidyl transferase-mediated deoxyuridine triphosphate nick-end}

Apoptosis was detected using a One Step TUNEL Apoptosis Assay Kit ( Beyotime Institute of Biotechnology, Shanghai, China) according to protocol. Briefly, cells were seeded on coverslips in 24-well plates at a density of cells for $24 \mathrm{~h}$. After fixing with $4 \%$ formaldehyde, the cells were washed with PBS and permeabilized using $0.2 \%$ Triton X-100. Following equilibration, cells were labeled using TdT reaction mix and incubated for $1 \mathrm{~h}$ at $37{ }^{\circ} \mathrm{C}$ in a humidified chamber. Subsequently, $2 \times \mathrm{SSC}$ were added for $15 \mathrm{~min}$ to stop the reaction. Apoptotic cells were detected using a Nikon Eclipse 90i microscope (Nikon Corporation; Tokyo, Japan).

\section{Statistical analysis}

All experiments were performed at least three times for each determination. Data are expressed as mean $\pm \mathrm{SD}$. Comparisons of parameters between 2 groups were made with unpaired Student $t$ test. Comparisons of parameters among 3 groups were made with one-way analysis of variance (ANOVA), followed by the Scheffe multiplecomparison test. Statistical analysis was carried out by using the SPSS 13.0 software. $P<0.05$ was regarded as significant statistical difference.

\section{ACKNOWLEDGMENTS}

We are grateful to Central Research Laboratory, the Second Hospital of Shandong University for 
technical assistance and the generous support. This work was supported by a grant from the National Natural Science Foundation of China (Grant No. 81500042), Natural Science Foundation of Shandong Province (Grant No. ZR2016HM67, 2013HQ047), Science and technology development project of Shandong (Grant No.2016GSF201044, 2016GSF201203).

\section{CONFLICTS OF INTEREST}

The authors declare no conflicts of interest.

\section{REFERENCES}

1. Yang J, Li X, Al-Lamki RS, Southwood M, Zhao J, Lever AM, Grimminger F, Schermuly RT, Morrell NW. Smaddependent and smad-independent induction of id1 by prostacyclin analogues inhibits proliferation of pulmonary artery smooth muscle cells in vitro and in vivo. Circ Res. 2010; 107:252-262.

2. Lavoie JR, Ormiston ML, Perez-Iratxeta C, Courtman DW, Jiang B, Ferrer E, Caruso P, Southwood M, Foster WS, Morrell NW, Stewart DJ. Proteomic analysis implicates translationally controlled tumor protein as a novel mediator of occlusive vascular remodeling in pulmonary arterial hypertension. Circulation. 2014; 129:2125-2135.

3. Pietra GG, Capron F, Stewart S, Leone O, Humbert M, Robbins IM, Reid LM, Tuder RM. Pathologic assessment of vasculopathies in pulmonary hypertension. J Am Coll Cardiol. 2004; 43:25S-32S.

4. Stenmark KR, Fagan KA, Frid MG. Hypoxia-induced pulmonary vascular remodeling: cellular and molecular mechanisms. Circ Res. 2006; 99:675-91.

5. Hosokawa S, Haraguchi G, Sasaki A, Arai H, Muto S, Itai A, Doi S, Mizutani S, Isobe M. Pathophysiological roles of nuclear factor kappa $\mathrm{B}(\mathrm{NF}-\kappa \mathrm{B})$ in pulmonary arterial hypertension: effects of synthetic selective NF- $\kappa \mathrm{B}$ inhibitor IMD-0354. Cardiovasc Res. 2013; 99:35-43.

6. Young KA, Ivester C, West J, Carr M, Rodman DM. BMP signaling controls PASMC KV channel expression in vitro and in vivo. Am J Physiol Lung Cell Mol Physiol. 2006; 290:L841-L848.

7. Hansmann G, de Jesus Perez VA, Alastalo TP, Alvira CM, Guignabert C, Bekker JM, Schellong S, Urashima T, Wang L, Morrell NW, Rabinovitch M. An antiproliferative BMP-2/PPARgamma/apoE axis in human and murine SMCs and its role in pulmonary hypertension. J Clin Invest. 2008; 118:1846-1857.

8. Atkinson C, Stewart S, Upton PD, Machado R, Thomson JR, Trembath RC, Morrell NW. Primary pulmonary hypertension is associated with reduced pulmonary vascular expression of type II bone morphogenetic protein receptor. Circulation. 2002; 105:1672-1678.
9. Dewachter L, Adnot S, Guignabert C, Tu L, Marcos E, Fadel E, Humbert M, Dartevelle P, Simonneau G, Naeije $\mathrm{R}$, Eddahibi S. Bone morphogenetic protein signalling in heritable versus idiopathic pulmonary hypertension. Eur Respir J. 2009; 34:1100-1110.

10. Zhang Y, Wang Y, Yang K, Tian L, Fu X, Wang Y, Sun Y, Jiang Q, Lu W, Wang J. BMP4 increases the expression of TRPC and basal $[\mathrm{Ca} 2+] \mathrm{i}$ via the p38MAPK and ERK1/2 pathways independent of BMPRII in PASMCs. PLoS One. 2014; 9:e112695.

11. Long L, Ormiston ML, Yang X, Southwood M, Gräf S, Machado RD, Mueller M, Kinzel B, Yung LM, Wilkinson JM, Moore SD, Drake KM, Aldred MA, et al. Selective enhancement of endothelial BMPR-II with BMP9 reverses pulmonary arterial hypertension. Nat Med. 2015; 21:777-785.

12. Luan Y, Chao S, Ju ZY, Wang J, Xue X, Qi TG, Cheng GH, Kong F. Therapeutic effects of baicalin on monocrotalineinduced pulmonary arterial hypertension by inhibiting inflammatory response. Int Immunopharmacol. 2015; 26:188-193.

13. Chen Y, Hui H, Yang H, Zhao K, Qin Y, Gu C, Wang X, Lu N, Guo Q. Wogonoside induces cell cycle arrest and differentiation by affecting expression and subcellular localization of PLSCR1 in AML cells. Blood. 2013; 121:3682-3691.

14. Woo AY, Cheng CH, Waye MM. Baicalein protects rat cardiomyocytes from hypoxia/reoxygenation damage via a prooxidant mechanism. Cardiovasc Res. 2005; 65:244-253.

15. Lin L, Wu XD, Davey AK, Wang J. The anti-inflammatory effect of baicalin on hypoxia/reoxygenation and TNF-alpha induced injury in cultural rat cardiomyocytes. Phytother Res. 2010; 24:429-437.

16. Zhang L, Pu Z, Wang J, Zhang Z, Hu D, Wang J. Baicalin inhibits hypoxia-induced pulmonary artery smooth muscle cell proliferation via the AKT/HIF-1 $\alpha /$ p27-associated pathway. Int J Mol Sci. 2014; 15:8153-8168.

17. Dong LH, Wen JK, Miao SB, Jia Z, Hu HJ, Sun RH. Baicalin inhibits PDGF-BB-stimulated vascular smooth muscle cell proliferation through suppressing PDGFR $\beta$ ERK signaling and increase in p27 accumulation and prevents injury-induced neointimal hyperplasia. Cell Res. 2010; 20:1252-1262.

18. Ikezoe T, Chen SS, Heber D, Taguchi H, Koeffler HP. Baicalin is a major component of PC-SPES which inhibits the proliferation of human cancer cells via apoptosis and cell cycle arrest. Prostate. 2001; 49:285-292.

19. D'Alto M, Mahadevan VS. Pulmonary arterial hypertension associated with congenital heart disease. Eur Respir Rev. 2012; 21:328-337.

20. Dai HL, Guo Y, Guang XF, Xiao ZC, Zhang M, Yin XL. The changes of serum angiotensin-converting enzyme 2 in patients with pulmonary arterial hypertension due to congenital heart disease. Cardiology. 2013; 124:208-212. 
21. Li L, Wei C, Kim IK, Janssen-Heininger Y, Gupta S. Inhibition of nuclear factor- $\kappa \mathrm{B}$ in the lungs prevents monocrotaline-induced pulmonary hypertension in mice. Hypertension. 2014; 63:1260-1269.

22. Zhang X, Wang ZS, Luan Y, Lin M, Zhu XB, Ma Y, Zhang ZH, Wang YB. The effect of PS-341 on pulmonary vascular remodeling in high blood flow-induced pulmonary hypertension. Int J Mol Med. 2014; 33:105-110.

23. Rabinovitch M. Molecular pathogenesis of pulmonary arterial hypertension. J Clin Invest. 2012; 122:4306-4313.

24. Morrell NW, Bloch DB, ten Dijke P, Goumans MJ, Hata A, Smith J, Yu PB, Bloch KD. Targeting BMP signalling in cardiovascular disease and anaemia. Nat Rev Cardiol. 2016; 13:106-120.

25. Lowery JW, Frump AL, Anderson L, Di Carlo GE, Jones MT, de Caestecker MP. ID family protein expression and regulation in hypoxic pulmonary hypertension. Am J Physiol Regul Integr Comp Physiol. 2010; 299:R1463-R1477.

26. Ciumas M, Eyries M, Poirier O, Maugenre S, Dierick F, Gambaryan N, Montagne K, Nadaud S, Soubrier F. Bone morphogenetic proteins protect pulmonary microvascular endothelial cells from apoptosis byupregulating $\alpha$-Bcrystallin. Arterioscler Thromb Vasc Biol. 2013; 33:2577-2584.

27. Kumar S, Wei C, Thomas CM, Kim IK, Seqqat R, Kumar R, Baker KM, Jones WK, Gupta S. Cardiac-specific genetic inhibition of nuclear factor- $\kappa \mathrm{B}$ prevents right ventricular hypertrophy induced by monocrotaline. Am J Physiol Heart Circ Physiol. 2012; 302:H1655-H1666.

28. Yang J, Li X, Al-Lamki RS, Southwood M, Zhao J, Lever AM, Grimminger F, Schermuly RT, Morrell NW. Smaddependent and smad-independent induction of id1 by prostacyclin analogues inhibits proliferation of pulmonary artery smooth muscle cells in vitro and in vivo. Circ Res. 2010; 107:252-262.

29. Courboulin A, Barrier M, Perreault T, Bonnet P, Tremblay VL, Paulin R, Tremblay E, Lambert C, Jacob MH, Bonnet SN, Provencher S, Bonnet S. Plumbagin reverses proliferation and resistance to apoptosis in experimental PAH. Eur Respir J. 2012; 40:618-629.

30. Yang X, Long L, Southwood M, Rudarakanchana N, Upton PD, Jeffery TK, Atkinson C, Chen H, Trembath RC, Morrell NW. Dysfunctional Smad signaling contributes to abnormal smooth muscle cell proliferation in familial pulmonary arterial hypertension. Circ Res. 2005; 96:1053-1063.

31. Yang J, Davies RJ, Southwood M, Long L, Yang XD, Sobolewski A, Upton PD, Trembath RC, Morrell NW. Mutations in bone morphogenetic protein type II receptor cause dysregulation of Id gene expression in pulmonary artery smooth muscle cells: implications for familial pulmonary arterial hypertension. Circ Res. 2008; 102:1212-1221.

32. Maruyama H, Dewachter C, Belhaj A, Rondelet B, Sakai S, Remmelink M, Vachiery JL, Naeije R, Dewachter L. Endothelin-bone morphogenetic protein type 2 receptor interaction induces pulmonary artery smooth muscle cell hyperplasia in pulmonary arterial hypertension. J Heart Lung Transplant. 2015; 34:468-478.

33. Hurst LA, Dunmore BJ, Long L, Crosby A, Al-Lamki R, Deighton J, Southwood M, Yang X, Nikolic MZ, Herrera B, Inman GJ, Bradley JR, Rana AA, Upton PD, Morrell NW. TNF $\alpha$ drives pulmonary arterial hypertension by suppressing the BMP type-II receptor and altering NOTCH signalling. Nat Commun. 2017; 8:14079.

34. Dorfmüller P, Humbert M, Perros F, Sanchez O, Simonneau G, Müller KM, Capron F. Fibrous remodeling of the pulmonary venous system in pulmonary arterial hypertension associated with connective tissue diseases. Hum Pathol. 2007; 38:893-902.

35. Soon E, Holmes AM, Treacy CM, Doughty NJ, Southgate L, Machado RD, Trembath RC, Jennings S, Barker L, Nicklin P, Walker C, Budd DC, Pepke-Zaba J, Morrell NW. Elevated levels of inflammatory cytokines predict survival in idiopathic and familial pulmonary arterial hypertension. Circulation. 2010; 122:920-927.

36. Costello CM, Howell K, Cahill E, McBryan J, Konigshoff M, Eickelberg O, Gaine S, Martin F, McLoughlin P. Lungselective gene responses to alveolar hypoxia: potential role for the bone morphogenetic antagonist gremlin in pulmonary hypertension. Am J Physiol Lung Cell Mol Physiol. 2008; 295:L272-L284.

37. Murphy N, Gaynor KU, Rowan SC, Walsh SM, Fabre A, Boylan J, Keane MP, McLoughlin P. Altered expression of bone morphogenetic protein accessory proteins in murine and human pulmonary fibrosis. Am J Pathol. 2016; 186:600-615.

38. Reynolds AM, Holmes MD, Danilov SM, Reynolds PN. Targeted gene delivery of BMPR2 attenuates pulmonary hypertension. Eur Respir J. 2012; 39:329-343.

39. Arciniegas E, Frid MG, Douglas IS, Stenmark KR. Perspectives on endothelial-to-mesenchymal transition: potential contribution to vascular remodeling in chronic pulmonary hypertension. Am J Physiol Lung Cell Mol Physiol. 2007; 293:L1-L8.

40. Willis BC, Borok Z. TGF-beta-induced EMT: mechanisms and implications for fibrotic lung disease. Am J Physiol Lung Cell Mol Physiol. 2007; 293:L525-L534.

41. Alastalo TP, Li M, Perez Vde J, Pham D, Sawada H, Wang JK, Koskenvuo M, Wang L, Freeman BA, Chang HY, Rabinovitch M. Disruption of PPAR $\gamma / \beta$-catenin-mediated regulation of apelin impairs BMP-induced mouse and human pulmonary arterial EC survival. J Clin Invest. 2011; 121:3735-3746. 